\title{
The Impact of Covid-19 on Mental Health: A Global Analysis of Publications
}

\author{
Sandeep Grover 1, ${ }^{1,}$, BM Gupta ${ }^{2}$, GM Mamdapur ${ }^{3}$, Swapnajeet Sahoo', Aseem Mehra' \\ 'Postgraduate Institute of Medical Education and Research, Department of Psychiatry, Chandigarh, INDIA. \\ ${ }^{2}$ Formerly with CSIR-NISTADS, New Delhi, INDIA \\ ${ }^{3}$ Synthite Industries (P) Ltd, Kolenchery, Kerala, INDIA.
}

\begin{abstract}
Covid-19 infection, which emerged in late 2019, spread across the world rapidly and was declared as a pandemic on $24^{\text {th }}$ March 2020 by the World Health Organization. Besides other implications, Covid-19 pandemic led to significant mental health issues in the general public, those infected with the virus and the health care workers. Over the period of 15-16 months, a significant amount of literature has emerged on the mental health issues in the context of Covid-19 pandemic. This paper aims to evaluate the research trends in mental health related to Covid-19 infection by using the bibliometric analysis. Using the Scopus database, as on $21^{\text {st }}$ of March 2021, 15,223 records focusing on "Covid-19 and Mental Health" were identified. The research on this theme averaged 8.90 citations per paper with $13.77 \%$ publications supported by funding agencies from global research agencies/firms were published. Researchers from 158 countries participated in mental health research on Covid-19, with top 12 countries accounting for $95.91 \%$ share of the global output and a major share of global citations in the subject. Although researchers from USA, U.K. and China led the global publication share (ranging from $10.40 \%$ to $26.56 \%$ ), but researchers from
\end{abstract}

China, France and Australia registered higher relative citation index (ranging from 1.19 to 2.31). Researchers from Harvard Medical School, USA, University of Toronto, Canada, and King's College, London, U.K. were the most productive (with 299, 270 and 222 papers). Researchers from the National University of Singapore (51.84 and 5.83), King's College, London, U.K. (27.23 and 3.06), Huazhong University of Science and Technology, China (23.65 and 2.66) were most impactful in terms of citation per paper and relative citation index. To conclude, this bibliometric analysis provides an overview of the extent of research activities in Covid-19 and mental health.

Key words: Covid-19, Mental Health, Global Publications, Scientometrics, Bibliometrics.

\section{Correspondence}

Dr. Sandeep Grover,

Professor, Department of Psychiatry, PGIMER-160012, Chandigarh, INDIA

Email id: drsandeepg2002@yahoo.com

DOI: 10.5530/jyp.2021.13s.72

\section{INTRODUCTION}

By the end of 2019, a coronavirus disease-19 (Covid-19) appeared in China, which later spread to almost all countries of the world and was recognized as a global pandemic by the World Health Organization by $24^{\text {th }}$ of March 2020. Covid-19 has led to substantial morbidity and mortality all over the world. This Covid-19 has impacted global public health, affecting various aspect of human life. Governments and the scientific community across the globe reacted promptly to the pandemic outbreak. The Covid-19 pandemic has prompted an explosion of publications in scientific and medical journals. Among the various themes on which the publications emerged on Covid-19, mental health was one of the important area of focus. It was seen that, the pandemic had significant negative impact on the mental health of general population at large, people who developed Covid-19 infection, who had recovered from Covid-19 infection and the health care workers involved in the care of people with Covid-19 infection. ${ }^{1}$ The initial publications emerged in the form of viewpoints, case reports, review articles, etc., but gradually, original articles and metanalysis and systematic reviews started emerging. ${ }^{2}$ Over the period a significant amount of literature has emerged on the mental health issues among patients with Covid-19. Hence, it is important to understand the trends in the research.

Some of the researchers have carried out bibliometric assessment of global literature on Covid-19 pandemic. Among such studies, one of the studies used bibliometric analyses to assess the mental health research output related to the Covid-19 pandemic and compared it with the literature output on the West Africa Ebola and H1N1 outbreaks published up to $26^{\text {th }}$ Aug 2020. The authors reported that despite the shorter time since the beginning of the Covid-19 pandemic, relative to Ebola and H1N1 (127 for Ebola and 327 for H1N1), a much greater number of publications on mental health related to Covid-19 $(\mathrm{n}=3070)$ had emerged. ${ }^{3}$ Gul et al. ${ }^{4}$ reviewed and analyzed the publishing trends (up to July 2020) on Covid-19 and mental health literature including top cited documents, productive countries, institutions, journals, authorship and collaboration, the most frequent keywords and funding bodies. This study included 277 publications, which were published in 195 journals and had received 738 citations. In terms of country output, it was seen that maximum number of publications emerged from United States of America (50 articles), whereas highest Citation Impact was for publications from China. The maximum number of publications were published in International journal of Environmental Research and Public Health and papers published in the later journal had also received highest number of citations. ${ }^{4}$

These bibliometric studies were done during the initial part of the pandemic, when research was limited to few countries. Hence, there is a need to evaluate the research output for a longer period of time to have a better understanding of the publication trends. Keeping this in mind, we decided to undertake the present study with the aim to study and perform a bibliometric analysis to identify the hotspots and research trends in mental health related to Covid-19 infection. We aimed to 
identity the most productive countries, organizations, authors, the commonly used keywords and to study the co-relationship linkages between them. We also aimed to identify the most productive journals and characteristics of high cited papers.

\section{METHODS}

To retrieve the publication data on "Impact of Covid-19 on Mental Health", the Scopus abstract and citation database was searched for all the indexed documents published up to 21 March 2021. A set of keywords related to Covid-19 were used for search and the Article Title or Keyword tags in Scopus database were used to identify the papers. The words used were as follows:

(TITLE ("COVID 19" OR "2019 novel coronavirus" OR "coronavirus 2019” OR “coronavirus disease 2019” OR “2019-novel CoV” OR “2019 ncov" OR "covid 2019" OR "covid19" OR "corona virus 2019" OR "ncov-2019” OR “ncov2019” OR “nCoV 2019” OR “2019-ncov" OR "covid-19" OR "Severe acute respiratory syndrome coronavirus 2" OR “SARS-CoV-2”) OR KEY (“COVID 19” OR “2019 novel coronavirus” OR “coronavirus 2019” OR “coronavirus disease 2019” OR “2019-novel CoV” OR "2019 ncov" OR "covid 2019" OR "covid19” OR "corona virus 2019" OR "ncov-2019” OR "ncov2019” OR "nCoV 2019” OR "2019-ncov" OR "covid-19" OR "Severe acute respiratory syndrome coronavirus 2" OR "SARS-CoV-2")) AND (mental AND health) AND (LIMIT-TO (PUBYEAR, 2021) OR LIMIT-TO (PUBYEAR, 2020)).

The bibliometric analysis yielded 15,223 records which were imported on 21 March 2021. The collected data were exported to Microsoft Excel for further analysis and assessment. The information which was extracted included: countries of origin, sources, titles, authors, year of publication, affiliations, type of document, fields of interest, funding sources, keywords, languages, citation frequency, etc.

We considered the number of published documents as a quantitative indicator that indicates the research productivity of an author, country, institution, source, etc. The impact of published works was assessed using various qualitative indicators (i.e., frequency of citations, average of citations, relative citation index and number of high cited papers). VOSviewer software tool was used for constructing and visualizing bibliometrics networks, and to analyze and visualize the networks of co-authorship relations between author, countries, and institution, and co-occurrence relations between keywords.

\section{Analysis}

\section{Publication Overview}

The global research output in the sub-field "Impact of Covid-19 on Mental Health"accumulated 15,223 publications which received 1,35,485 citations, averaging 8.9 citations per paper (CPP) during 2020-21. Of the 15,223 global publications on this subject, of which 2097 (13.77\%) had received funding support from 200 research agencies and industrial firms. The 2097 funded papers received 23230 citations, averaging 11.08 CPP. The major agencies providing funds in this area were: National Institute of Health (305 papers), National Natural Science Foundation of China (263 papers), National Institute of Health Research (127 papers), The Brazilian National Council for Scientific and Technological Development (80 papers), Canadian Institute of health Research (64 papers), National Institute of Drug Abuse (64 papers), Wellcome Trust (63 papers), etc. Of the funded papers, 93 agencies supported 1-10 publications each, 63 agencies supported 11-20 papers each, 29 agencies supported 21-50 papers each, 11 agencies supported 51-100 papers and 4 agencies funded 122-305 papers.

Of the total publications by document types, the most common type of publications were original articles $(n=10,210 ; 67.07 \%)$, and this were followed by reviews and/or metanalysis ( $n=1591 ; 10.45 \%)$, letters $(n=1574 ; 10.34 \%)$, notes $(n=8165 ; 5.36 \%)$, editorials $(4.88 \%)$, conference papers $(0.95 \%)$, short surveys $(0.55 \%)$, erratum $(0.18 \%)$, miscellaneous papers $(0.22 \%)$. Of the total papers, $96.63 \%$ (14710) papers were published in English, and this was followed by papers published in Spanish $(1.57 \% ; n=239)$, French $(0.74 \% ; n=112)$, German $(0.58 \% ; n=89)$, Chinese $(0.54 \% ; n=82)$, Portuguese $(0.51 \% ; n=77)$, and 22 other languages (with 1-47 papers in each language).

\section{Top 12 Countries}

Overall, 158 countries unevenly participated in "Impact of Covid-19 on Mental Health" research, with researchers from 63 countries publishing 1-10 papers each, researchers from 18 countries publishing 11-20 papers each, researchers from 34 countries publishing 21-100 papers each, researchers from 33 countries publishing 101-500 papers each, researchers from 5 countries publishing 501-1000 papers each and those from 5 countries publishing 1113-4074 papers each.

The $95.91 \%$ share of the global research output emerged from top 12 most productive countries alone. Researcher from United States (26.56\%), United Kingdom (13.32\%), and China (10.40\%) were among the highest contributors to the global publication share. Research from five countries registered relative citation index above the global average (1.09) and these countries were China (2.31), France (1.27), Australia (1.19), United Kingdom (1.16) and Canada (1.13) (Table 1, Figure 1).

\section{Collaboration among Top 12 Countries}

All the top 12 countries had one to one collaborative linkages (Table 2). The top three countries with largest collaborative linkages (2096, 1611 and 1156) were United States, United Kingdom and Australia. Among country-country collaborative linkages, researchers from United StatesUnited Kingdom registered highest number of collaborative linkages $(n=388)$, followed by United States-China $(n=260)$, USA-Canada $(n=257)$, USA-Italy $(n=234)$, etc. With the aid of the app VOSviewer, the analysis of collaborative linkages with other countries publications showed that the highest number of publications came from United States, followed by United Kingdom and China (Figure 1).

\section{Important Keywords}

The top 28 keywords which appeared in literature on "Impact of Covid-19 on Mental Health" are shown in (Table 3). In terms of specific diagnosis or psychological phenomenon, anxiety followed by depression were the 2 most common keywords in the literature. Further there was significant cooccurance of the keywords in different publications (Figure 2).

\section{Most Productive and Impactful Organizations}

Overall, the research emerged from 1606 organizations, which was unevenly distributed, with researchers from 1020 organizations publishing 1-10 papers each, researchers from 480 organizations publishing 11-50 papers each, researchers from 87 organizations publishing 51-100 papers, researchers from 16 organizations publishing 101-200 papers each and researchers from 3 organizations publishing 201-302 papers each. Among top 25 organizations, 7 were from United States, 4 from Australia, 3 from United Kingdom, 2 each from Canada, China and Italy and 1 each from Brazil, France, India, Iran and Singapore. The productivity of top 25 most productive organizations varied from 93 to 299 publications per organization; together they contributed $22.69 \%$ (3454) global publications share and $32.81 \%(44,446)$ global citations share. Table 4 lists top 8 most productive and 8 most impactful organizations. It was observed that, out of the 25 most productive organizations, researchers from 8 organizations contributed more than average global publications 
Table 1: Top 12 Countries Research Contribution on “Impact of Covid-19 on Mental Health” during 2020-21.

\begin{tabular}{|c|c|c|c|c|c|c|c|c|}
\hline S.No & Name of the Country & TP & $\%$ TP & TC & CPP & ICP & \%ICP & $\mathrm{RCl}$ \\
\hline 1 & USA & 4043 & 26.56 & 26578 & 6.57 & 1561 & 38.61 & 0.84 \\
\hline 2 & U.K. & 2027 & 13.32 & 18323 & 9.04 & 1120 & 55.25 & 1.16 \\
\hline 3 & China & 1525 & 10.02 & 27486 & 18.02 & 616 & 40.39 & 2.31 \\
\hline 4 & Italy & 1273 & 8.36 & 10843 & 8.52 & 561 & 44.07 & 1.09 \\
\hline 5 & India & 1113 & 7.31 & 5956 & 5.35 & 331 & 29.74 & 0.69 \\
\hline 6 & Australia & 926 & 6.08 & 8607 & 9.29 & 573 & 61.88 & 1.19 \\
\hline 7 & Canada & 915 & 6.01 & 8056 & 8.80 & 504 & 55.08 & 1.13 \\
\hline 8 & Spain & 760 & 4.99 & 4862 & 6.40 & 376 & 49.47 & 0.82 \\
\hline 9 & Germany & 570 & 3.74 & 3441 & 6.04 & 321 & 56.32 & 0.77 \\
\hline 10 & Brazil & 547 & 3.59 & 3440 & 6.29 & 249 & 45.52 & 0.81 \\
\hline 11 & Iran & 465 & 3.05 & 2436 & 5.24 & 168 & 36.13 & 0.67 \\
\hline \multirow[t]{4}{*}{12} & France & 436 & 2.86 & 4330 & 9.93 & 196 & 44.95 & 1.27 \\
\hline & Total of top 12 countries & 14600 & 95.91 & 124358 & 8.52 & 6576 & 45.04 & 1.09 \\
\hline & Global total & 15223 & 100.00 & 118739 & 7.80 & & & \\
\hline & Share of top 12 countries in global total & 95.91 & & & & & & \\
\hline
\end{tabular}

${ }^{*} \mathrm{TP}=$ Total Publications; TC=Total Citations; $\mathrm{CPP}=$ Citations per Paper; ICP=International Collaborative Publications; RCI=Relative Citation Index

Table 2: Collaboration Linkages among Top 12 Countries during 2020-21.

\begin{tabular}{|c|c|c|c|}
\hline S.No & $\begin{array}{l}\text { Name } \\
\text { of the } \\
\text { Country }\end{array}$ & $\begin{array}{l}\text { Number of Collaborative Linkages with } \\
\text { Other Countries }\end{array}$ & $\mathrm{TCL}(\mathrm{NOC})$ \\
\hline 1 & USA & $\begin{array}{l}\text { 2(388), 3(260), 4(234), 5(144), 6(228), } \\
7(257), 8(132), 9(138), 10(120), 11(82) \\
12(113)\end{array}$ & $2096(11)$ \\
\hline 2 & U.K. & $\begin{array}{l}\text { 1(388), 3(102), 4(214), 5(98), 6(207), } \\
7(161), 8(135), 9(114), 10(83), 11(57), \\
12(102)\end{array}$ & $1611(11)$ \\
\hline 3 & China & $\begin{array}{l}1(260), 2(102), 4(48), 5(22), 6(100), 7(72), \\
8(35), 9(33), 10(27), 11(19), 12(13)\end{array}$ & $731(11)$ \\
\hline 4 & Italy & $\begin{array}{l}\text { 1(234), 2(214), 3(48), 5(44), 6(83), 7(69), } \\
8(136), 9(101), 10(61), 11(35), 12(101)\end{array}$ & $1126(11)$ \\
\hline 5 & India & $\begin{array}{l}1(144), 2(98), 3(22), 4(44), 6(56), 7(40) \\
8(28), 9(27), 10(37), 11(27), 12(19)\end{array}$ & $542(11)$ \\
\hline 6 & Australia & $\begin{array}{l}1(228), 2(207), 3(100), 4(83), 5(56), 7(96), \\
8(41), 9(53), 10(36), 11(18), 12(38)\end{array}$ & $1156(11)$ \\
\hline 7 & Canada & $\begin{array}{l}1(257), 2(161), 3(72), 4(69), 5(40), 6(96) \\
8(50), 9(53), 10(48), 11(31), 12(55)\end{array}$ & $932(11)$ \\
\hline 8 & Spain & $\begin{array}{l}\text { 1(132), 2(135), 3(35), 4(136), 5(28), 6(41), } \\
7(50), 9(53), 10(68), 11(25), 12(80)\end{array}$ & $863(11)$ \\
\hline 9 & Germany & $\begin{array}{l}\text { 1(138), 2(114), 3(33), 4(101), 5(27), 6(53), } \\
7(53), 8(53), 10(33), 11(19), 12(57)\end{array}$ & $681(11)$ \\
\hline 10 & Brazil & $\begin{array}{l}\text { 1(120), 2(83), 3(27),4(61), 5(37), 6(36), } \\
7(48), 8(68), 9(33), 11(20), 12(27)\end{array}$ & $560(11)$ \\
\hline 11 & Iran & $\begin{array}{l}\text { 1(82), 2(57), 3(19), 4(35), 5(27), 6(18), } \\
7(31), 8(25), 9(19), 10(20), 12(13)\end{array}$ & $346(11)$ \\
\hline 12 & France & $\begin{array}{l}\text { 1(113), 2(102), 3(13), 4(101), 5(19), 6(38), } \\
7(55), 8(80), 9(57), 10(27), 11(13)\end{array}$ & $538(11)$ \\
\hline
\end{tabular}

$\mathrm{TCL}=$ Total Collaborative Linkages; NOC=Number of Countries

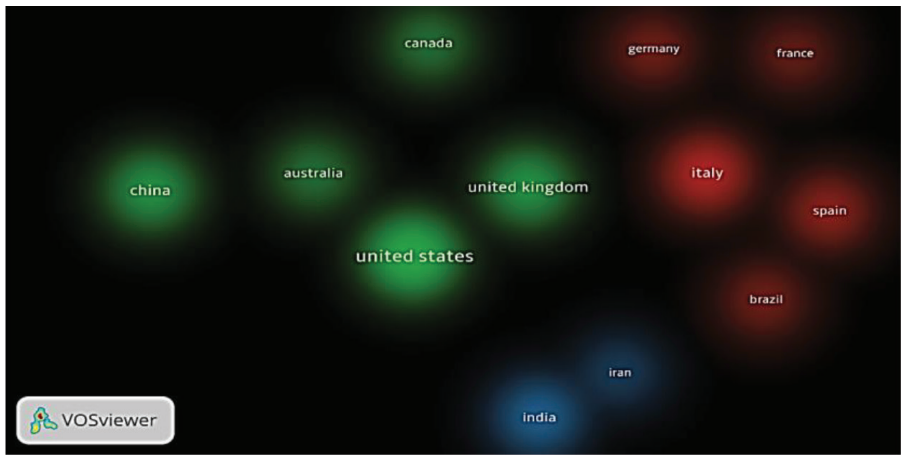

Figure 1: Density visualization map for no. of collaborative linkages with other countries countries (The minimum was set at 1 document per country and included 12 countries. Countries with the highest number of publications have darker spot. In the map, the United States, United Kingdom and China had the darkest spots, i.e. highest publications).

(138.16) and researchers from 9 organizations registered citation impact per paper and relative citation index more than average of the 25 organizations (12.87 and 1.45).

\section{Collaborative Linkages among top 25 organizations}

All the top 25 organizations had one to one collaborative linkages (Table 5). The top three organizations with largest collaborative linkages (164, 155 and 144) were Harvard Medical School, United States, Massachusetts General Hospital, United States and Brigham and Women's Hospital, United States. Among organization-organization collaborative linkages, Huazhong University of Science and Technology, China Tongji Medical College, China had registered highest number of collaborative linkages $(n=132)$, followed by Harvard Medical School, United States -Massachusetts General Hospital, United States $(n=85)$, Harvard Medical School, United States - Brigham and Women's Hospital, United States $(n=83)$, King's College, London, United Kingdom-University 
Table 3: List of top 20 Most Frequently Appearing Keywords.

\begin{tabular}{|c|c|c|c|c|c|c|c|}
\hline S.No & Name of the Keyword & Frequency & VOS. Cluster & S.No & Name of the Keyword & Frequency & VOS. Cluster \\
\hline 1 & Covid-19 & 13516 & 2 (green) & 15 & Social Support & 655 & 2 (green) \\
\hline 2 & Mental Health & 3895 & 1 (red) & 16 & Lockdown & 604 & 1 (red) \\
\hline 3 & Anxiety & 2942 & 3 (blue) & 17 & Psychological Wellbeing & 584 & 1 (red) \\
\hline 4 & Depression & 2267 & 3 (blue) & 18 & Posttraumatic Stress & 569 & 3 (blue) \\
\hline 5 & Quarantine & 1484 & 1 (red) & 19 & Mental Health care & 447 & 1 (red) \\
\hline 6 & Mental Stress & 1318 & 2 (green) & 20 & Loneliness & 397 & 1 (red) \\
\hline 7 & Mental Disease & 1334 & 1 (red) & 21 & Insomnia & 397 & 3 (blue) \\
\hline 8 & Social Isolation & 1045 & 1 (red) & 22 & Psychological Adaptation & 383 & 2 (green) \\
\hline 9 & Psychological Stress & 1117 & 2 (green) & 23 & Psychological Resilience & 372 & 2 (green) \\
\hline 10 & Social Distancing & 811 & 1 (red) & 24 & Emotion & 302 & 2 (green) \\
\hline 11 & Mental Health Service & 713 & 1 (red) & 25 & Pregnancy & 291 & 4 (yellow) \\
\hline 12 & Distress Syndrome & 666 & 3 (blue) & 26 & Suicide & 284 & 1 (red) \\
\hline 13 & Copying Behavior & 665 & 2 (green) & 27 & Job Stress & 274 & 2 (green) \\
\hline 14 & Fear & 655 & 3 (blue) & 28 & Sleep Disorder & 274 & 3 (blue) \\
\hline
\end{tabular}

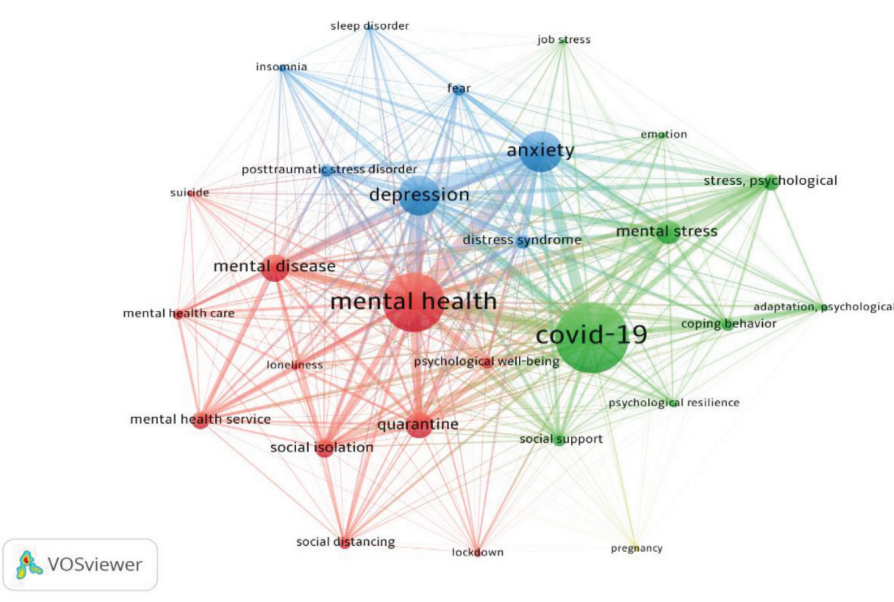

Figure 2: Visualization network on top 28 keyword co-occurrence (The overlay visualization helped to understand the evolution of research. The size of the nodes and keywords represents the weights of the nodes. The cooccurrence of keywords using VOSviewer software was investigated over the entire analyzed period. After being analyzed, there were 4 clusters (red colour with 11 items, green colour with 9 items, blue with 7 items and yellow 1 items respectively).

College London, United Kingdom ( $\mathrm{n}=34)$, University of Melbourne, Australia -Monash University, Australia $(n=31)$, Massachusetts General Hospital, United States - Brigham and Women's Hospital, United States $(n=21)$, University of Toronto, Canada - University of British Columbia, Canada $(n=20)$, etc. (Table 6).

\section{Top 25 Most Productive Authors}

2353 authors unevenly participated in global research on "Impact of Covid-19 on Mental Health": 2043 authors published 1-5 papers each, 224 authors published 6-10 papers each, 79 authors published 11-20 papers each and 7 authors published 21-42 papers each. Among top 25 authors, 6 were from India, 4 each were from USA and France, 3 from Germany, 2 each from Italy and Macau and 1 each from Bangladesh, Hong Kong, Iran and Sweden. The research productivity of top 25 most productive authors varied from 15 to 42 publications per author.
Together they contributed 3.26\% (496) global publications share and 9.86\% (13,361) global citations share during 2020-21 (Table 6).

\section{Medium of Research Communication}

15074 (99.02\%) of the global research output on "impact of Covid-19 on mental health" appeared in 1393 journals. Of the 1393 journals (reporting 15074 articles), 732 journals published 1-5 papers each, 420 journals published 6-10 papers each, 132 journals published 11-20 papers each, 73 journals published 21-50 papers each, 14 journals published 51-100 papers each, and 11 published 101-568 papers each. The top 25 most productive journals accounted for $22.61 \%$ (3408) share of global publications in journals. International Journal of Environmental Research and Public Health was the top most productive journal (with 582 papers) in reporting global research on this theme, followed by Frontiers in Psychology (310 papers), Frontiers in Psychiatry (252 papers), Asian Journal of Psychiatry (246 papers), Psychiatry Research (221 papers), PLOS One (215 papers), Journal of Medical Internet Research (135 papers), Frontiers In Public Health (121 papers), Lancet Psychiatry (119 papers) and Psychological Trauma Theory Research Practice And Policy (114 papers).

\section{DISCUSSION}

This paper analyzes the research on "impact of Covid-19 on Mental Health" based on select bibliometric indicators for 2019-21. The findings of this bibliometric study provides insights into the publications which have emerged in the area of mental health in the current ongoing Covid-19 pandemic. This study shows that in a short duration of about 13-14 months, 15,223 global publications emerged on impact of Covid-19 mental health. This findings suggest that Covid-19 related mental health research has expanded rapidly. This could be due to the fact that many journals promoted rapid publication of Covid related research in the beginning of the pandemic to expand the knowledge about the topic, possibly to help clinicians across the globe, manage the mental health issues which emerged with the ongoing Covid-19 pandemic. However, this approach of rapid publication has been criticized by some of the authors, who suggest that this rapid proliferation led to publication of many poor quality research, in terms of the writing style, the content of the studies/papers and the duplication of research..$^{5-9}$ On the other hand some of the authors have actually professed for such 
Table 4: Scientometric Profile of Top 8 Most Productive and Top 8 Most Impactful Global Organizations on “Impact of Covid-19 on Mental Health" Research.

\begin{tabular}{|c|c|c|c|c|c|c|c|c|}
\hline S.No & Name of the Organization & TP & TC & CPP & $\mathrm{HI}$ & ICP & \%ICP & $\mathrm{RCl}$ \\
\hline \multicolumn{9}{|c|}{ Top 8 Most Productive Organizations } \\
\hline 1 & Harvard Medical School, USA & 299 & 1794 & 6.00 & 22 & 137 & 45.82 & 0.67 \\
\hline 2 & University of Toronto, Canada & 270 & 2943 & 10.90 & 24 & 143 & 52.96 & 1.22 \\
\hline 3 & King's College, London, U.K. & 222 & 6044 & 27.23 & 23 & 127 & 57.21 & 3.06 \\
\hline 4 & University College London, U.K. & 177 & 2769 & 15.64 & 21 & 110 & 62.15 & 1.76 \\
\hline 5 & Università degli Studi di Roma La Sapienza, Italy & 176 & 1809 & 10.28 & 20 & 50 & 28.41 & 1.15 \\
\hline 6 & University of Melbourne, Australia & 167 & 2188 & 13.10 & 20 & 103 & 61.68 & 1.47 \\
\hline 7 & Huazhong University of Science and Technology, China & 153 & 3618 & 23.65 & 22 & 51 & 33.33 & 2.66 \\
\hline 8 & Tongji Medical College, China & 149 & 3182 & 21.36 & 21 & 51 & 34.23 & 2.40 \\
\hline \multicolumn{9}{|c|}{ Top 8 Most Impactful Organizations } \\
\hline 1 & National University of Singapore & 96 & 4977 & 51.84 & 20 & 63 & 65.63 & 5.83 \\
\hline 2 & King’s College, London, U.K. & 222 & 6044 & 27.23 & 23 & 127 & 57.21 & 3.06 \\
\hline 3 & Huazhong University of Science and Technology, China & 153 & 3618 & 23.65 & 22 & 51 & 33.33 & 2.66 \\
\hline 4 & Tongji Medical College, China & 149 & 3182 & 21.36 & 21 & 51 & 34.23 & 2.40 \\
\hline 5 & INSERM, France & 126 & 2058 & 16.33 & 21 & 62 & 49.21 & 1.84 \\
\hline 6 & University College London, U.K. & 177 & 2769 & 15.64 & 21 & 110 & 62.15 & 1.76 \\
\hline 7 & University of Oxford, U.K. & 136 & 2094 & 15.40 & 16 & 98 & 72.06 & 1.73 \\
\hline 8 & John Hopkins Bloomberg School of Public Health, USA & 100 & 1504 & 15.04 & 17 & 59 & 59.00 & 1.69 \\
\hline
\end{tabular}

${ }^{*} \mathrm{TP}=$ Total Publications; $\mathrm{TC}=$ Total Citations; $\mathrm{CPP}=$ Citations per Paper; HI=Herch Index; RCI=Relative Citation Index

rapid expansion of the literature and open access to the research, so that this could aid in rapid corrective steps to provide proper direction to the results. Others have suggested methods to improve the same. ${ }^{10}$

Overall, the research emerged from 158 countries across the globe, with top 12 most productive countries accounting for $95.91 \%$ share of the global output and for the major share of global citations in the subject. In terms of specific countries, United States, United Kingdom and China accounted for $26.56 \%, 13.32 \%$ and $10.40 \%$ respectively to the global publication. These findings suggest that, although research has emerged from about three-fourth of the countries across the globe, the research output on mental health issues has been limited to few countries, which often lead the world in the area of research. ${ }^{11}$

The average citation impact for each published paper was 8.9 citations per paper. Out of the total publications, 138 papers $(0.91 \%$ share of global output) were considered as highly cited papers. When one looks at these data, it is apparent that rapid publication of the literature did help in upsurge of the citations of the papers.

In terms of the research topics, maximum research has focused on depression and anxiety, as it was seen to be present across all groups and in all involved, i.e., general population, persons with Covid-19 infection, health care workers and those who have recovered from Covid-19 infection. Other topics which were addressed in many papers included quarantine, social isolation and social distancing. However, relatively less research emerged on the positive aspects of mental well-being and the interventions to address the mental health issues encountered during the pandemic. These findings suggest that after the initial studies on epidemiology of various mental health issues, possibly in near future there would be a change in focus of research, with more and more research focusing on interventions related to addressing the mental health issues encountered during the pandemic.

In terms of number of authors and organizations contributing to the research output, it was evident that 1606 organizations and 2353 authors participated in the Covid-19 mental health research. However, like other indexes, the distribution of research output was skewed in terms of the number of participating organizations. The top 25 organizations and top 25 authors contributed $22.69 \%$ and $3.26 \%$ share in global publications and $32.81 \%$ and $9.86 \%$ share in global citations share respectively. In terms of specific institutes, Harvard Medical School, USA, University of Toronto, Canada, King's College, London, U.K., University College London, U.K. and Universitadeglistudi di Roma La Sapienza, Italy led in the publication productivity (with 299, 270, 222, 177 and 176 papers). In terms of the most impactful organizations in terms of citation per paper and relative citation index, National University of Singapore (51.84 and 5.83), King's College, London, U.K.( 27.23 and 3.06), Huazhong University of Science and Technology, China (23.65 and 2.66), Tongji Medical College, China (21.36 and 2.40) and INSERM, France (16.33 and 1.84) were at the top of the list. However, in terms of most productive authors, M.D.Griffiths, S.Grover, T.Cheung, Y.T. Xiang and D. Banerjee were the most productive authors with $42,28,25,25$ and 24 papers. If one looks at this profile, it is evident that, the most productive authors were not limited to countries like United States and United Kingdom, but included researchers from China and India. In terms of most impactful authors, N.Greenberg (163.94 and 18.42), Y.T. Xiang (81.64 and 9.17), J.R.Lechien (65.2 and 7.33), T.Cheung (63.52 and 7.14) and A.H.Pakpour (37.72 and 4.24) were the most impactful authors.

The impact and the citations of various publications are influenced by the quality of the paper and possibly by its early publication. As the pandemic emerged in China, the authors from this country possibly showed path to researchers from different parts of the world. In terms of the various journals, which published the Covid-19 related research, International Journal of Environmental Research and Public Health, Frontiers In Psychology, Frontiers in Psychiatry, Asian Journal of Psychiatry and Psychiatry Research topped the list with maximum number of publications (with 582, 310, 252, 246 and 221 papers) on the 


\section{Table 5: Extent of Collaborative Linkages among Top 25 Organizations.}

\begin{tabular}{|c|c|c|c|}
\hline S.No & Name of the Organization & $\begin{array}{l}\text { Number of Collaborative Linkages with top } 30 \text { other } \\
\text { organizations }\end{array}$ & $\begin{array}{c}\mathrm{TCL} \\
\text { (NOO) }\end{array}$ \\
\hline 1 & Harvard Medical School, USA & $\begin{array}{l}\text { 2(18), 6(13), 7(6), 8(5), 9(10), 10(12), 12(85), 13(1), 15(4), 16(10), } \\
17(17), 18(83), 20(9), 21(3), 22(3), 23(10), 25(6)\end{array}$ & 295(17) \\
\hline 2 & University of Toronto, Canada & $\begin{array}{l}1(18), 3(10), 4(6), 6(11), 9(9), 10(6), 12(7), 13(3), 14(20), 15(3), \\
16(3), 17(9), 18(2), 19(10), 20(8), 21(3), 22(3), 24(3)\end{array}$ & $134(18)$ \\
\hline 3 & King’s College, London, U.K. & $\begin{array}{l}1(8), 2(10), 4(34), 6(9), 9(11), 11(9), 12(6), 13(3), 14(4), 15(3), 17(3), \\
18(3), 19(7), 20(2), 22(2), 24(3), 25(3)\end{array}$ & $110(17)$ \\
\hline 4 & University College London, U.K. & $\begin{array}{l}1(7), 2(6), 3(34), 6(7), 9(13), 10(7), 12(3), 14(2), 15(3), 16(3), 17(3) \\
18(2), 19(6), 21(2), 23(3), 24(8), 25(2)\end{array}$ & $111(17)$ \\
\hline 5 & Universitadeglistudi di Roma La Sapienza, Italy & $11(1), 21(2), 22(14)$ & $17(3)$ \\
\hline 6 & University of Melbourne, Australia & $\begin{array}{l}\text { 1(13), 3(9), 10(31), 13(3), 14(5), 16(4), 17(2), 18(7), 19(13), 20(2), } \\
24(13)\end{array}$ & $102(5)$ \\
\hline 7 & Huazhong University of Science and Technology, China & $1(6), 8(132)$ & $138(2)$ \\
\hline 8 & Tongji Medical College, China & 1(5), 7(132), 18(4), 20(1), 23(1) & $143(5)$ \\
\hline 9 & University of Oxford, U.K. & $\begin{array}{l}\text { 1(10), 2(9), 3(11), 4(13), 6(8), 10(6), 11(4), 12(4), 15(4), 16(4), 9(2), } \\
18(2), 19(6), 21(2), 23(2), 24(2)\end{array}$ & $89(16)$ \\
\hline 10 & Monash University, Australia & $\begin{array}{l}\text { 1(12), 2(6), 3(2), 4(7), 6(31), 9(6), 12(3), 15(4), 18(8), 19(13), 20(2), } \\
21(3), 24(13)\end{array}$ & $110(13)$ \\
\hline 11 & INSERM, France & $1(3), 3(9), 9(4), 12(2), 16(5)$ & $23(5)$ \\
\hline 12 & Massachusetts General Hospital, USA & $\begin{array}{l}1(85), 2(7), 3(6), 4(3), 9(4), 10(3), 11(2), 14(2), 15(2), 17(10), 18(21) \\
19(2), 20(3), 21(2), 22(2), 25(1)\end{array}$ & $155(16)$ \\
\hline 13 & National Institute of Mental Health and Allied Sciences, India & $2(3), 3(3), 6(3), 19(3)$ & $12(4)$ \\
\hline 14 & University of British Columbia, Canada & 2(20), 3(4), 4(2), 6(5), 21(5) & $36(5)$ \\
\hline 15 & University of Sao Paulo, Brazil & $1(4), 2(3), 3(3), 9(4), 10(4), 11(2), 12(2), 21(2)$ & $24(8)$ \\
\hline 16 & University of Washington, Seattle, USA & $\begin{array}{l}\text { 1(10), 2(3), 4(3), 4(3), 6(4), 9(4), 10(5), 17(5), 18(4), 21(2), 22(2), } \\
24(2)\end{array}$ & $47(12)$ \\
\hline 17 & University of California, San Francisco, USA & $\begin{array}{l}\text { 1(17), 2(9), 3(3), 4(3), 6(2), 9(2), 12(10), 16(5), 18(2), 19(2), 20(2), } \\
24(2), 25(2)\end{array}$ & $61(13)$ \\
\hline 18 & Brigham and Women's Hospital, USA & $\begin{array}{l}\text { 1(83), 2(2), 3(3), 4(2), 6(7), 8(4), 9(2), 10(8), 12(21), 16(4), 17(2), } \\
\text { 20(3), 25(3) }\end{array}$ & $144(13)$ \\
\hline 19 & University of New South Wales, Sydney, Australia & $\begin{array}{l}2(10), 3(7), 4(6), 6(13), 9(6), 10(13), 12(2), 13(3), 17(2), 21(2), 22(3) \\
24(19), 21(2), 22(3), 23(3)\end{array}$ & $94(15)$ \\
\hline 20 & John Hopkins Bloomberg School of Public Health, USA & $\begin{array}{l}\text { 1(9), 2(8), 3(2), 6(2), 8(1), 10(2), 12(3), 17(2), 18(3), 23(17), 25(4), } \\
23(17), 25(4)\end{array}$ & $75(13)$ \\
\hline 21 & Tehran University of Medical Sciences, Iran & 1(3), 2(3), 4(2), 5(2), 9(2), 10(3), 12(2), 14(5), 15(2), 16(2), 19(2) & $28(11)$ \\
\hline 22 & Universitadeglistudi di Milano, Italy & $1(3), 2(3), 3(2), 5(14), 12(2), 16(2), 19(3), 24(2)$ & $31(8)$ \\
\hline 23 & National University of Singapore & 1(2), 2(10), 4(3), 8(1), 9(2), 10(2), 11(2), 19(3), 20(17) & $42(9)$ \\
\hline 24 & University of Sydney, Australia & 2(3), 3(3), 4(8), 6(13),9(2), 10(13), 16(2),17(2), 19(19), 22(2) & $67(10)$ \\
\hline 25 & Columbia University in the City of New York, USA & 1(6), 3(3), 4(2), 12(1), 17(2), 18(3), 20(4) & $21(7)$ \\
\hline
\end{tabular}

$\mathrm{TCL}=$ Total Collaborative Linkages; $\mathrm{NOO}=$ Number of Organizations. The number in the third column refers to the name of the institute listed in the column and the number in the parenthesis indicates the number of linkage.

topic. This finding suggest that the many psychiatry journals dedicated their space to the Covid related research to help researchers across the globe to publish their data. In terms of citations per paper, Brain Behavior and Immunity (60.37) topped the list and this was followed by Lancet Psychiatry (46.92), Psychiatry Research (20.99), International Journal of Mental Health and Addiction (19.99), Asian Journal of Psychiatry (12.76), British Medical Journal (BMJ) (12.56). This finding is in contrast to the ranking of various journals by impact factors for the year 2018 and suggest that the journals which encouraged rapid publication of Covid-19 related research are going to see and upsurge in their impact factor in the upcoming years.
Our study has certain limitations. First the search strategy was limited to the Scopus search engine, which could have led to exclusion of certain publications, especially those published in journals not listed in the Scopus data base and those published in regional languages. Further, this study did not make any attempt to evaluate the quality of the research, but focused only on the various research indicators. The citation counts were also limited to Scopus search engine, which usually records lower number of citations, compared to search engines like google scholar. Accordingly, our search could have led to underestimation of citation indexes. 
Table 6: Scientometric Profile of Top 8 Most Productive and 8 Most Impactful Global Authors "Impact of Covid-19 on Mental Health" Research during 2020-21.

\begin{tabular}{|c|c|c|c|c|c|c|c|c|c|}
\hline S.No & $\begin{array}{l}\text { Name of the } \\
\text { Author }\end{array}$ & Affiliation of the Author & TP & TC & CPP & $\mathrm{HI}$ & ICP & $\%$ ICP & $\mathrm{RCl}$ \\
\hline \multicolumn{10}{|c|}{ Top 8 Most Productive Authors } \\
\hline 1 & M.D.Griffiths & Nottingham Trent University, U.K & 42 & 1147 & 27.31 & 14 & 42 & 100.00 & 3.07 \\
\hline 2 & S.Grover & $\begin{array}{l}\text { Postgraduate Institute of Medical Education and } \\
\text { Research, Chandigarh, India }\end{array}$ & 28 & 154 & 5.50 & 7 & 2 & 7.14 & 0.62 \\
\hline 3 & T.Cheung & Hong Kong Polytechnic University & 25 & 1588 & 63.52 & 10 & 23 & 92.00 & 7.14 \\
\hline 4 & Y.T. Xiang & University of Macau & 25 & 2041 & 81.64 & 10 & 22 & 88.00 & 9.17 \\
\hline 5 & D.Banerjee & $\begin{array}{l}\text { National Institute of Mental Health and Allied } \\
\text { Sciences, Bangalore, India }\end{array}$ & 24 & 271 & 11.29 & 6 & 4 & 16.67 & 1.27 \\
\hline 6 & A.Mehra & $\begin{array}{l}\text { Postgraduate Institute of Medical Education and } \\
\text { Research, Chandigarh, India }\end{array}$ & 23 & 151 & 6.57 & 7 & 2 & 8.70 & 0.74 \\
\hline 7 & S.Sahoo & $\begin{array}{l}\text { Postgraduate Institute of Medical Education and } \\
\text { Research, Chandigarh, India }\end{array}$ & 23 & 151 & 6.57 & 7 & 2 & 8.70 & 0.74 \\
\hline 8 & M.A.Mamun & $\begin{array}{l}\text { Center for Health Innovation, Networking and } \\
\text { Research, Bangladesh }\end{array}$ & 20 & 548 & 27.40 & 10 & 17 & 85.00 & 3.08 \\
\hline \multicolumn{10}{|c|}{ Top 8 Most Impactful Authors } \\
\hline 1 & N.Greenberg & King's College, London, U.K. & 17 & 2787 & 163.94 & 6 & 2 & 11.76 & 18.42 \\
\hline 2 & Y.T. Xiang & University of Macau & 25 & 2041 & 81.64 & 10 & 22 & 88.00 & 9.17 \\
\hline 3 & J.R.Lechien & Université libre de Bruxelles ULB, Italy & 15 & 978 & 65.20 & 6 & 15 & 100.00 & 7.33 \\
\hline 4 & T.Cheung & Hong Kong Polytechnic University & 25 & 1588 & 63.52 & 10 & 23 & 92.00 & 7.14 \\
\hline 5 & A.H.Pakpour & Jonkoping University, Sweden & 18 & 679 & 37.72 & 11 & 18 & 100.00 & 4.24 \\
\hline 6 & M.A.Mamun & $\begin{array}{l}\text { Center for Health Innovation, Networking and } \\
\text { Research, Bangladesh }\end{array}$ & 20 & 548 & 27.40 & 10 & 17 & 85.00 & 3.08 \\
\hline 7 & M.D.Griffiths & Nottingham Trent University, U.K & 42 & 1147 & 27.31 & 14 & 42 & 100.00 & 3.07 \\
\hline 8 & S.K.Kar & King Georg's Medical University, Lucknow, India & 18 & 437 & 24.28 & 7 & 12 & 66.67 & 2.73 \\
\hline
\end{tabular}

TP=Total Publications; TC=Total Citations; CPP=Citations per Paper; HI=Herch Index; ICP=International Collaborative Papers; RCI=Relative Citation Index

\section{CONCLUSION}

To conclude, this bibliometric analysis provides an overview of the extent of research activities in Covid-19 and mental health including the key actors (i.e. authors and institutions) and major research areas in the field. This study shows that Covid-19 mental health research was not limited to the traditional top researchers or top institutes of the world, but had wider research landscape. This study provides researchers and relevant stakeholders with a good starting point in developing further research and maximizing existing research networks that can be tailored towards addressing the critical gaps in the research.

\section{CONFLICT OF INTEREST}

The authors declare that there is no conflict of interest.

\section{REFERENCES}

1. Grover S, Dua D, Sahoo S, Mehra A, Nehra R, Chakrabarti S. Why all Covid-19 hospitals should have mental health professionals: the importance of mental health in a worldwide crisis! Asian J Psychiatr. 2020;51:102147. doi: 10.1016/j. ajp.2020.102147.

2. Tandon R. The bitter lessons of Covid-19: acknowledging and working through many points of tension. Asian J Psychiatr. 2021:55:102545. doi: 10.1016/j. ajp.2021.102545.
3. Maalouf FT, Mdawar B, Meho LI, AkI EA. Mental health research in response to the Covid-19, Ebola, and H1N1 outbreaks: A comparative bibliometric analysis. J Psychiatr Res. 2021;132:198-206. doi: 10.1016/j.jpsychires.2020.10.018, PMID 33131830

4. Gul S, Rehman SU, Ashiq M, Khattak A. Mapping the scientific literature on Covid-19 and mental health. Psychiatr Danub. 2020;32(3-4):463-71. doi: 10.24869/psyd.2020.463, PMID 33370754.

5. Dobler CC. Poor quality research and clinical practice during Covid-19. Breathe (Sheff). 2020;16(2):200112. doi: 10.1183/20734735.0112-2020.

6. Nieto I, Navas JF, Vázquez C. The quality of research on mental health related to the Covid-19 pandemic: A note of caution after a systematic review. Brain Behav Immun Health. 2020;7:100123. doi: 10.1016/j.bbih.2020.100123.

7. Perillat L, Baigrie BS. Covid-19 and the generation of novel scientific knowledge: research questions and study designs. J Eval Clin Pract. 2021;27(3):694-707. doi: 10.1111/jep.13550, PMID 33590660.

8. Federico A. Scientific publishing in the Covid-19 era: successes and pitfalls. Neurol Sci. 2020;41(7):1643-5. doi: 10.1007/s10072-020-04550-y, PMID 32617739.

9. Vlasschaert C, Topf JM, Hiremath S. Proliferation of papers and preprints during the coronavirus Disease 2019 pandemic: progress or problems with peer review? Adv Chronic Kidney Dis. 2020;27(5):418-26. doi: 10.1053/j. ackd.2020.08.003, PMID 33308508.

10. Lachapelle F. Covid-19. Preprints of the and their publishing rate: an improved method [preprint]. Infect Dis (except HIV/AIDS). 2020. doi: 10.1101/2020.09.04.20188771.

11. Saxena S, Paraje G, Sharan P, Karam G, Sadana R. The 10/90 divide in mental health research: trends over a 10-year period. Br J Psychiatry. 2006;188(1):81-2. doi: 10.1192/bjp.bp.105.011221, PMID 16388075. 